\title{
Integrins as a distinct subtype of dependence receptors
}

\author{
DG Stupack ${ }^{\star, 1}$ \\ 1 Department of Pathology, UCSD School of Medicine \& Moore's UCSD \\ Comprehensive Cancer Center 3855 Health Sciences Drive MC 0803 La Jolla, \\ CA 92093-0803, USA \\ * Corresponding author: DG Stupack, Department of Pathology, University of \\ California, San Diego, 9500 Gilman Drive, La Jolla, CA 92037, USA. \\ Tel: 858822 1150; Fax: 858822 2630; E-mail: dstupack@gmail.com
}

Received 01.2.05; revised 16.3.05; accepted 23.3.05; published online 03.6 .05 Edited by P Mehlen

\begin{abstract}
In the absence of their cognate ligand, dependence receptors trigger programmed cell death. This function is the defining feature of dependence receptors, which include members of several different protein families. The integrins are a family of heterodimeric receptors for extracellular matrix (ECM) proteins, mediating cell anchorage and migration. Integrins share characteristics with dependence receptors, and integrin binding to substrate ECM ligands is essential for cell survival. Although integrins do not conform in all characteristics to the established definitions of dependence receptors, alterations in the expression of integrins and their ligands during physiological and pathological events, such as wound healing, angiogenesis and tumorigenesis, do regulate cell fate in a ligand-dependent manner. This biosensory function of integrins fits well with our current concept of dependence receptor action, and thus integrins may rightly be considered to comprise a distinct subclass of dependence receptor.
\end{abstract}

Cell Death and Differentiation (2005) 12, 1021-1030.

doi:10.1038/sj.cdd.4401658; published online 3 June 2005

Keywords: integrin; extracellular matrix; apoptosis; dependence receptor

Abbreviations: ECM, extracellular matrix; IMD, integrinmediated death; $\mathrm{DCC}$, deleted in colon cancer; RET, rearranged during transfection; UNC5H, uncoordinated-5 homolog

\section{Introduction}

Cell survival is governed by a diverse array of stimuli that converge on common signaling pathways. These signals regulate cytosolic and nuclear events in a coordinated, cellspecific manner. Signaling events have been considered to act through cell surface receptors to transduce cytosolic signals via the actions of tyrosine and serine/threonine kinases, or by eliciting 'second messengers' such as $\mathrm{Ca}^{+2}$ and CAMP. $^{1-3}$ However, a relatively new concept termed 'dependence' has been applied to a growing number of receptors. ${ }^{4}$ Dependence receptors, generally, maintain the capacity to elicit cell signaling events similar to the 'classic' receptors, but also maintain a capacity to signal 'negatively' in the absence of their cognate ligand.

In the absence of ligand, 'classical' signaling receptors tend to be relatively inert, demonstrating no signaling function. When overexpressed, these receptors may promote signaling events even in the absence of their ligand. ${ }^{5,6}$ Deletion or inhibition of these receptors will often eliminate a cell's capacity to respond to the receptor's ligand(s). In contrast, dependence receptors have been shown to promote programmed cell death in the absence of their appropriate ligand. This creates the cellular state from which they draw their name $^{4}$ (i.e., the cells are 'dependent' upon the presence of a trophic ligand to survive). Accordingly, de novo expression (or overexpression) of dependence receptors, in the absence of appropriate ligands, promotes cell death. ${ }^{7,8}$ In the presence of ligand, signaling and/or cell differentiation is observed. Ablation of dependence receptor expression will generally eliminate the requirement for ligand, and similarly promote cell survival (if not differentiation). However, increased cell survival can disrupt tissue homeostasis and may have significant pathological consequences, such as neoplasia.

Well-studied examples of dependence receptors include the neurotrophin receptor $\left(\mathrm{p} 75^{\mathrm{NTR}}\right)$, the netrin receptors $\mathrm{DCC}$ (deleted in colon cancer) and UNC5H (uncoordinated-5 homolog) proteins, as well as RET (rearranged during transfection), a receptor for glial-derived neurotrophic factor (GDNF). ${ }^{4}$ These receptors (and other putative dependence receptors) typically belong to different protein families, but are functionally linked by their capacity to regulate cell survival in response to a trophic factor, governing cellular homeostasis and preserving the integrity of specific tissues. This appears to be a control mechanism used by vertebrate cells to regulate developmental processes and tissue homeostasis, as receptor homologs in invertebrates do not appear to share these functions. ${ }^{4,8}$ Despite this basic initial understanding of dependence, the nuances of dependence receptor signaling continue to be uncovered. As our understanding of this process increases, new variations on the central theme of 'dependence receptors' continue to be described.

\section{The integrins}

In this respect, the integrin family of cell adhesion receptors appear to have many properties in common with dependence receptors. ${ }^{4}$ The $18 \alpha$ and $8 \beta$ integrin subunits form at least 24 heterodimeric $(\alpha / \beta)$ receptors (Table 1 ), each of which binds to its own limited subset of extracellular matrix (ECM) and/or 
Table 1 ECM Ligands and their integrin receptors

\begin{tabular}{|c|c|c|}
\hline Ligand & Integrins & Notes \\
\hline Collagens & $\alpha 1 \beta 1, \alpha 2 \beta 1, \alpha 10 \beta 1, \alpha 11 \beta 1$ & $\begin{array}{l}\text { Principally receptors for collagens, integrins } \alpha 1 \beta 1 \text { and } \\
\alpha 2 \beta 1 \text { may bind other ligands with a lesser affinity. }\end{array}$ \\
\hline Laminins & $\alpha 3 \beta 1, \alpha 6 \beta 1, \alpha 6 \beta 4, \alpha 7 \beta 1$ & $\begin{array}{l}\text { Principally receptors for laminins, integrin } \alpha 3 \beta 1 \text { may } \\
\text { bind other ligands with a lesser affinity. }\end{array}$ \\
\hline 'RGD'-containing proteins & $\alpha 5 \beta 1, \alpha 8 \beta 1, \alpha \operatorname{ll} b \beta 3, \alpha \mathrm{v} \beta 1, \alpha \mathrm{v} \beta 3, \alpha \mathrm{v} \beta 5, \alpha \mathrm{v} \beta 6, \alpha \mathrm{v} \beta 8$ & $\begin{array}{l}\text { Each integrin binds its own subset of the RGD- } \\
\text { containing ligands (which include fibronectin, fibrin and } \\
\text { vitronectin). Some bind additional ligands in an RGD- } \\
\text { independent manner. }\end{array}$ \\
\hline $\begin{array}{l}\text { Immunoglobulin } \\
\text { superfamily proteins }\end{array}$ & $\alpha \mathrm{D} \beta 2, \alpha \mathrm{E} \beta 7, \alpha \mathrm{L} \beta 2, \alpha \mathrm{M} \beta 2, \alpha \mathrm{X} \beta 2, \alpha 4 \beta 1, \alpha 4 \beta 7, \alpha 9 \beta 1$ & $\begin{array}{l}\text { In addition to specific IGSF ligands (VCAM, ICAMs), } \\
\text { many of these integrins bind additional ligands. For } \\
\text { example, integrin } \alpha 4 \beta 1 \text { binds to fibronectin in an RGD- } \\
\text { independent manner, while } \alpha \mathrm{M} \beta 2 \text { and } \alpha \mathrm{X} \beta 2 \text { bind fibrin. }\end{array}$ \\
\hline
\end{tabular}

cell-surface ligands. ${ }^{9}$ These include structural ECM proteins, such as collagens, fibronectins, and laminins, as well as provisional ECM proteins that are deposited during tissue remodeling and thrombotic events, such as fibrin, vitronectin, tenascin and osteopontin. While integrins are expressed on essentially all tissues, the repertoire ${ }^{10}$ and ligand-binding activity ${ }^{11}$ of a specific $(\alpha / \beta)$ integrin heterodimer is regulated by the tissue and individual cell type that express it. Indeed, no cell expresses all integrins. Rather, cells tend to express integrins that are matched to the ECM ligands present within their local microenvironment. ${ }^{12}$ This matched expression of adhesion receptor and ECM ligand is also observed during developmental ${ }^{13,14}$ and tissue remodeling events. ${ }^{15}$ In these cases, the repertoire of specific integrins expressed on a given cell type is altered to adjust to concurrent changes within the local ECM. ${ }^{16}$ It is important to note that these alterations in the expression of specific integrin heterodimers have been implicated in the regulation of cell survival during tissue remodeling events in development and disease. ${ }^{13,17,18}$ Since the changing composition of the ECM dictates which integrins can be ligated, the local ECM functions as a trophic factor. Interestingly, a number of other trophic factors are also sequestered within the ECM, using binding sites distinct from those mediating cell anchorage. ${ }^{19-22}$ Given this central role of the ECM, it is perhaps not surprising that disruption of integrin interaction with the ECM (i.e., ligand deprivation) compromises cell survival.

\section{Anoikis: apoptosis due to the lack of integrin- mediated survival signals}

In their role as the principle cellular receptors for the ECM, integrins serve to mediate cell anchorage to the underlying ECM substrate, and to regulate cell morphology. ${ }^{23}$ The most extreme case of integrin 'ligand-deprivation' occurs after complete loss of cell contact with the substrate, and results in programmed cell death. ${ }^{24}$ Early studies by Frisch and Francis $^{25}$ termed the form of programmed cell death resulting from complete loss of substrate ECM contact 'anoikis'. Anoikis was suppressed in some cells by direct stimulation with the cytokine Scatter Factor, or via surrogate activation of growth factor receptor signaling pathways with oncogenes such as v-Src or ha-Ras. Anoikis could also be suppressed by integrin-mediated attachment to Arg-Gly-Asp (RGD)-containing ligands, but not by soluble RGD peptides. These studies agreed well with those of Meredith et al., ${ }^{26}$ who had shown that substrate attachment without integrin engagement resulted in programmed cell death, while integrin-mediated attachment rescued cell survival. Although integrins possess no intrinsic kinase activity, tyrosine kinase activity was implicated as a critical factor in ECM-mediated survival. However, integrin binding to substrate ECM elicits signaling via associated nonreceptor tyrosine kinases, including members of the focal adhesion kinase (FAK, PYK2) and Src kinase families, ${ }^{27}$ thus providing a mechanism to explain how integrins regulate cell survival.

While these studies agree with our current concept of integrin-mediated signaling, it is now appreciated that integrin ligation initiates several parallel, but interconnected, signaling cascades. Ligation of immobilized ECM by integrins promotes signaling via the Akt, Erk1/2 and JNK pathways (Figure 1), each of which have several well-documented roles in the regulation of cell survival and proliferation, as well as cell migration. Interestingly, however, similar cell types often respond differently to the deprivation of ECM substrate, and tend to undergo programmed cell death with varying kinetics via differing mechanisms. ${ }^{24,28}$ These studies suggested that the phenomenon was not actually a single death signal, but rather was a collection of different apoptotic cascades that were coordinately induced. Thus, anoikis occurs in any particular cell type in a manner dependent upon which apoptotic cascade is dominant in that cell. There is logic to anoikis for this reason; if only a single death pathway was responsible for inducing apoptosis after loss of substrate adhesion, then the loss of anchorage dependence by transformed cells might be acquired far more easily, with dire consequences for the host.

The requirement for ligation by an appropriate ligand (substrate ECM) and the capacity to mediate cell signaling and differentiation are characteristics of a dependence receptor. ${ }^{19}$ However, death triggered via anoikis occurs as the consequence of 'missing' survival signals (a passive event), while dependence receptors actively trigger apoptosis selectively in response to the absence of their trophic factor, irrespective of other changes in the cell. Moreover, anoikis is induced by widespread changes in cell infrastructure that disrupt a number of different biochemical signaling pathways. 


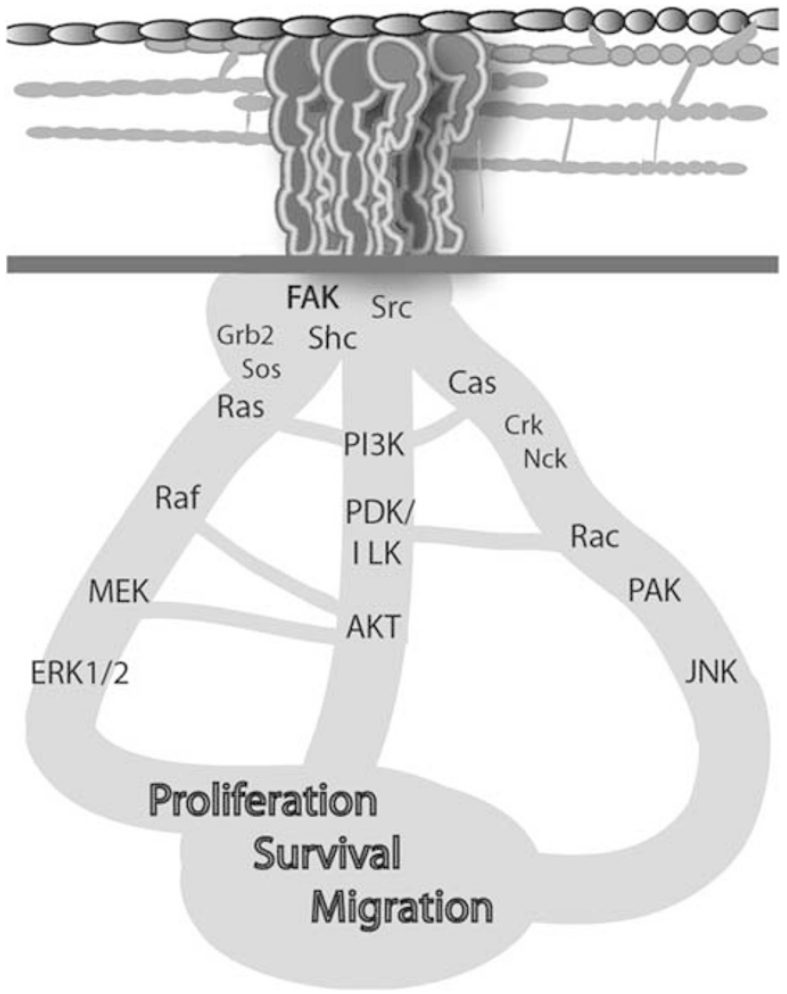

Figure 1 Integrin ligation initiates several signaling pathways. The integrins, depicted as $\alpha / \beta$ heterodimers, induce a number of cell signaling events when ligated to a substrate ECM. Integrin signaling via the Akt and two mitogenactivated protein kinase cascades (to ERK and JNK) is depicted. These signals collaborate to govern cellular proliferation, migration and survival. (ILK, integrinlinked kinases, PI3K, phosphoinnositide $3^{\prime}$ kinase, Cas, crk-associated substrate, ERK, extracellular-regulated kinase, JNK, Jun amino terminal kinase, PDK, P21. dependent kinase)

By contrast, dependence receptors promote cell death selectively in response to withdrawal of a specific cognate ligand, and initiate apoptosis via a defined mechanism. Thus, one might question whether the induction of 'anoikis' fits well with the current concept of dependence receptor action.

\section{Integrins and the ECM as trophic survival factors}

Integrins regulate cell survival in additional ways. Lack of expression of a given integrin (or integrins) can simply prevent attachment to a given ECM substrate. Since each integrin heterodimer binds only a limited subset of ECM ligands, attachment to any given ECM component typically requires expression of at least one type of integrin heterodimer appropriate for that ECM protein. For example, integrin $\alpha 3 \beta 1, \alpha 6 \beta 1, \alpha 6 \beta 4$ and $\alpha 7 \beta 1$ are the major laminin-binding integrins, and are commonly found on cells in contact with laminin in vivo. Three of these laminin-binding integrins are present on epidermal epithelial cells adjacent to (laminin-rich) basal lamina. Loss of expression of these integrins is associated with keratinocyte displacement from the lamina, differentiation and cell death. ${ }^{18}$ Given the importance of substrate attachment in cell survival discussed above, it is perhaps not surprising to find that the repertoire of integrin heterodimers expressed on a cell is matched to the ligands present in the local microenvironment.

Nevertheless, the regulation of integrin-mediated cell survival is more complex than a simple model of 'ligandbinding or not' might indicate. Integrin ligation promotes downstream changes in the cell that are essential for 'integrinspecific' signaling and survival effects. A global event triggered by integrin ligation is the process of 'cell spreading,' in which a spheroid cells flattens to increase surface area with underlying substrate ECM. Spreading is dependent on signaling from Rho family GTPases to the actin cytoskeleton, eliciting the extension of lamellapodia and pseudopodia. ${ }^{29}$ In pioneering studies, Ingber and co-workers documented the critical role of these downstream events in regulating cell survival. In an elegant series of investigations using microprinted patterns of ECM ligands, it was shown that the ligation of integrins by substrate ligands was insufficient, per se, to maintain cell viability. ${ }^{23}$ Cells were observed to undergo apoptosis when they were geometrically constrained on a small surface area, yet survived and proliferated when allowed to spread. Interestingly, these events occurred despite a similar overall quantity of available ligand for the integrins in each case. Thus, cell spreading and cell geometry contribute to regulating cell viability. Both elements are downstream of integrin signaling.

This capacity to attach and spread on ECM has a general positive impact on cell survival, increasing cell resistance to a variety of proapoptotic insults. In fact, cell attachment to ECM proteins has been associated with increased survival among cells exposed to radiation and chemotherapeutic agents, ${ }^{30}$ death receptor agonists ${ }^{31-33}$ and even among cells following withdrawal of growth factors. ${ }^{34,35}$ These studies indicate that while integrin ligation alone is insufficient to ensure cell survival, integrin ligation with a substrate ECM triggers critical secondary events that generally inhibit the induction of apoptosis. Thus, cellular interaction with the ECM provides critical information to the cell regarding the nature of its microenvironment. The cellular interpretation of this information then influences the propensity for a cell to survive or undergo apoptosis, as appropriate.

\section{General signaling events initiated by integrins}

Initially recognized as simple ECM-binding proteins, ${ }^{36}$ integrins are now appreciated to elicit several cell signaling events. The canonical integrin-activated signaling pathway involves activation of an apical nonreceptor tyrosine kinase such as $\mathrm{FAK}^{37}$ or a Src-family kinase, ${ }^{38}$ which in turn promote activation of small GTPases of the Ras and Rho families, leading to the downstream activation of MAPK (mitogenactivated proteins kinase) cascades $^{39}$ (Figure 1). Aside from immediate effects on cytosolic and cytoskeletal elements, these signaling cascades also regulate transcription events in the cell nucleus, ${ }^{40}$ and have profound effects upon cell viability. Integrin-mediated signaling has been linked to a number of factors directly governing cell resistance to apoptosis, including cell cycle progression ${ }^{10}$ and p53 activation, ${ }^{35} \mathrm{Bcl}-2$ family protein expression, ${ }^{34}$ death receptor and death ligand expression ${ }^{41,42}$ and regulation of the PI3K/Akt/ GSK $\beta$ axis. ${ }^{43}$ Moreover, these signaling events also influence 
cellular production of extracellular proteins, such as osteopontin ${ }^{44}$ and intracellular adaptors, such as osteoprotegerin ${ }^{45}$ and $c$-flip, ${ }^{42}$ which themselves act directly or indirectly to regulate cell survival.

As mentioned above, the small GTPases of the Rho family are critical for the cytoskeletal remodeling events that occur during substrate-ECM binding. ${ }^{29} \mathrm{Cdc} 42$, rac and rho play prominent roles in governing the extension of cellular processes $^{46}$ as well as regulating the application of mechanical tension to assist in anchoring, or moving, the cell. ${ }^{47}$ Protein phosphorylation events are maximal during cytoskeletal rearrangements such as pseudopod extension ${ }^{48}$ and cell spreading, ${ }^{49}$ and fall to low, or in some cases undetectable, levels in fully spread cells. Apical kinases such as FAK regulate the turnover of cell-substrate contacts (focal adhesions), which appear to initiate the small GTPAse cascades. Interestingly, FAK phosphorylation is maximal after ECM attachment but concomitant with the onset of cell spreading. ${ }^{50}$ This turnover of focal contacts is common to both cell spreading and migration, and is important in cell motility in response to motogenic factors. ${ }^{27}$ Interestingly, at least in some cases, the onset of the motility response is coupled with cell resistance to apoptosis. ${ }^{51}$

\section{Integrins coordinate 'classic' receptor- signaling pathways}

Many motogenic growth factors act in an integrin-dependent fashion. ${ }^{26}$ Thus, growth factors such as epidermal growth factor, vascular endothelial cell growth factor and plateletderived growth factor require integrin-substrate ligation to effect signaling. ${ }^{10}$ Interestingly, nonmigratory cells exposed to the growth factors present in tissue culture medium appear to undergo continuous rearrangement of focal adhesions, despite remaining in place. ${ }^{52}$ Since the receptors for these growth factors have been shown to physically associate with integrins, ${ }^{53,54}$ it is tempting to speculate that integrins may function as 'coreceptors' for these growth factors. Ironically then, these growth factor receptors, which have been suggested to function via 'classic' on/off signaling mechanisms, are actually integrin-dependent. Integrins, in turn, are dependent upon the composition of the substrate ECM.

This 'dependence' of growth factors upon integrins has been logically extended to the concept that integrin antagonism disrupts the signaling of the integrin-associated growth factor, ${ }^{55,56}$ which impacts cell survival. Disruption of growth factor signaling would seem most likely if the target integrin to be antagonized was so critical as to compromise the capacity of the cell to remain in contact with its ECM substrate, since loss of attachment promotes anoikis. ${ }^{24}$ It is worth noting, however, that the ECM present in tissues in vivo is typically complex, consisting of a number of distinct proteins bound by several different integrins. Moreover, cells often express more than one integrin that can bind a given ECM component. Therefore, the antagonism of a single type of integrin heterodimer does not necessarily compromise substrate attachment, or signaling events, that are mediated by other integrins. For example, integrin $\alpha \mathrm{v} \beta 3$ has been described to associate laterally with VEGF receptor 2 in endothelial cells. ${ }^{53}$ Nevertheless, endothelial cells express at least eight different integrin heterodimers, ${ }^{16}$ and antagonists of integrin $\alpha \mathrm{v} \beta 3$ do not influence cell attachment to ligands of other integrins present on the cell. Collagen is bound principally by integrin $\alpha 2 \beta 1$ in endothelial cells. Antagonism of $\alpha \mathrm{v} \beta 3$ does not prevent responsiveness to VEGF among collagen-adherent cells. ${ }^{57}$ However, among endothelial cells bound to fibrin, antagonism of integrin $\alpha \mathrm{v} \beta 3$ influences with both adhesion and signaling events. ${ }^{55}$ The requirement for a particular integrin to promote signaling events in response to a growth factor is therefore likely to be influenced by the ECM composition of the local microenvironment.

Cell responsiveness to growth factors in an ECM-dependent context provides one 'mechanistic' explanation for the general observation that integrin expression is matched to the local ECM environment for a given cell. Moreover, it provides a rationale for the transient alterations in integrin expression observed during tissue remodeling events, concurrent with the presence of stimulatory growth factors and the dynamic turnover and deposition of new ECM. All of these observations seem to fit the concept of a 'dependence' receptor. ${ }^{4}$

\section{Antagonized integrins promote apoptosis of adherent cells}

If integrins act as dependence receptors, it follows that the expression of unligated integrins should promote apoptosis, independent of macroscopic changes in cell morphology, such as detachment. In vivo, this would be expected to occur only if the repertoire of integrin heterodimers expressed on a given cell was poorly matched to the local ECM environment. Alternatively, appropriate integrins might be prevented from binding the ECM by other means, such as by the presence of soluble integrin antagonists. In fact, apoptosis does occur under these circumstances. ${ }^{15,58-60}$ Cell surface expression of integrins in the antagonized ${ }^{60}$ or unligated state ${ }^{58}$ can promote apoptosis among otherwise attached and 'spread' cells.

Using the example presented in the previous section, endothelial cells expressing integrins $\alpha 2 \beta 1$ and $\alpha \mathrm{v} \beta 3$ can readily attach to, and spread on, a collagen gel. Collagen provides a ligand for $\alpha 2 \beta 1$ (but not $\alpha \mathrm{v} \beta 3$ ), permitting signaling events and cell spreading to occur. However, the endothelial cells will nonetheless undergo apoptosis on this matrix. This process, which we termed IMD (integrin-mediated death), can be initiated by unligated or antagonized integrin $\beta$ ( $\beta 3$ and $\beta 1$ ) subunits. The unligated $\alpha \mathrm{v} \beta 3$ receptors appear to form clusters on the surface of the cells that colocalize with caspase activity. ${ }^{58}$ Unligated or antagonized $\alpha \mathrm{v} \beta 3$ integrins associate with caspase $8 .^{58,61}$ Indeed, in many cases in vivo, antagonism or nonligation of integrins promote caspase 8dependent apoptosis. ${ }^{62,63}$ These observations suggest that at least a subgroup of integrins may 'require' ligation to maintain cell viability, thus functioning as 'dependence' receptors.

An apparent mechanistic difference between integrins and canonical dependence receptors, however, is that integrins are associated with the cytoskeleton and act as 'mechanically' coupled receptors. ${ }^{64}$ Integrins require an immobilized substrate ligand (or other tensional force) to promote sustained 
signaling and cytoskeletal remodeling. Thus, although the presence of a soluble netrin may be sufficient to promote survival of cells expressing the dependence receptor DCC, ${ }^{65}$ soluble integrin ligands are generally insufficient to maintain cell survival, and instead tend to act as antagonists which prevent engagement of substrate ligands, thus promoting integrin-mediated death.

A subtle difference may also be indicated by the observation that during IMD, unligated integrins, or 'unligatable' integrin fusion proteins, have been observed to accumulate and form clusters on the surface of dying cells (or possibly on endosomes just below the cell surface). ${ }^{58}$ It is not clear whether this clustering facilitates apoptosis, or whether it is simply a byproduct of the programmed cell death pathway, although clustering of cell-surface integrins with antibody results in caspase 8 recruitment. ${ }^{58}$ If clustering is required for initiation, then this presents another subtle difference between integrins and DCC-type dependence receptors, which are not proapoptotic when clustered.

\section{Unligated integrins recruit caspase 8}

Unligated or antagonized integrins, like dependence receptors, recruit caspases, ${ }^{58}$ and this recruitment is critical to trigger programmed cell death. Unlike DCC, UNC5Hs and RET, which promote apoptosis via direct association with caspase 9 and subsequent cleavage and liberation of a cytoslolic addiction/dependence domain, unligated integrins initiate a caspase 8-dependent pathway. ${ }^{61,63,66-68}$ The colocalization and coprecipitation of caspase 8 with unligated integrins has been shown. ${ }^{58,61}$ However, pull-down type studies using recombinant GST-integrin cytosolic domains suggest that this interaction is not a simple $1: 1$ stoichiometric binding, or alternatively results from an indirect interaction with a third protein in the integrin-associated complex (unpublished observations). In either case, integrins differs from the known Netrin/NTF/GDNF type of canonical dependence receptors, which induce apoptosis in a caspase 9- depedent manner and with apparently simple stoichiometry. ${ }^{4}$ However, integrin-mediated death is similar to apoptosis induced by the $\beta$-amyloid precursor protein (APP), a dependence receptor which initiates apoptosis via activation of caspase $8^{69}$ and also happens to associate with integrins at sites of ECM contact. ${ }^{70}$ Interestingly, substrate-ECM contact may also prevent apoptosis induced by APP.

\section{Proteolytic cleavage of the integrin cytosolic domain}

Unlike DCC, RET and other dependence receptors, the $\beta$-integrins and APP bear relatively short cytosolic domains. Both also contain a cytosolic NPXY motif, and lack traditional cytosolic addiction/dependence domains (ADD) described in other dependence receptors. ${ }^{4}$ Both APP and $\beta$-integrins are processed via cytosolic proteases; caspases in the case of APP and APP-like proteins, and calpain in the case of integrins. ${ }^{71}$ However, there is a significant difference between the two at this point. In the case of APP, the protease-liberated cytosolic peptide is proapoptotic, ${ }^{69}$ while in the case of the integrin, expression of the free cytosolic domain of integrin does not. In fact, the cytosolic domain of integrin requires membrane localization to promote apoptosis, ${ }^{58}$ and it is possible that calpain-mediated cleavage of the $\beta$-integrin cytosolic domain observed in ECM-deprived cells may even act to delay apoptosis by preventing IMD. ${ }^{72}$ Despite these differences, the parallels between the APP and integrin systems are compelling, and the functional colocalization of the receptors leaves open the possibility that these elements may act coordinately to regulate the same 'dependence pathway.' A comparison of integrins and canonical dependence receptors is shown in Table 2.

\section{Integrins as 'modular' receptors}

There is an additional matter to consider when one compares integrins to classical dependence receptors. The short

Table 2 A comparison of integrins with canonical dependence receptors

\begin{tabular}{|c|c|c|}
\hline & Integrins & Canonical dependence receptors \\
\hline $\begin{array}{l}\text { Signaling } \\
\text { Activate MAPK } \\
\text { Suppress p53 activity } \\
\text { Cooperative signaling with growth factors } \\
\text { ERK-feedback regulates receptor activity } \\
\text { Activation of small GTPase-mediated actin remodeling } \\
\text { Requires a substrate-immobilized ligand }\end{array}$ & $\begin{array}{l}\text { Yes } \\
\text { Yes }(\alpha v \beta 3) \\
\text { Yes } \\
\text { Yes } \\
\text { Yes } \\
\text { Yes }\end{array}$ & $\begin{array}{l}\text { Yes (DCC, RET) } \\
\text { Yes (UNC5H) } \\
\text { Yes (APP) } \\
\text { Yes (APP) } \\
\text { Yes (DCC) } \\
\text { No }\end{array}$ \\
\hline $\begin{array}{l}\text { Apoptosis } \\
\text { Proapoptotic when unligated or antagonized } \\
\text { Requires cytosolic domain } \\
\text { Cleavage of cytosolic domain for apoptosis } \\
\text { Receptor clustering prevents apoptosis } \\
\text { Soluble ligand prevents apoptosis } \\
\text { Apoptosis via caspase } 8 \\
\text { Apoptosis via caspase } 9\end{array}$ & $\begin{array}{l}\text { Yes }(\alpha \mathrm{v} \beta 3, \alpha 5 \beta 1, \alpha 3 \beta 1) \\
\text { Yes } \\
\text { No } \\
\text { No } \\
\text { No } \\
\text { Yes } \\
\text { Yes }^{b}\end{array}$ & $\begin{array}{l}\text { Yes } \\
\text { Yes } \\
\text { Yes } \\
\text { Yes } \\
\text { Yes } \\
\text { Yes (APP) } \\
\text { Yes (DCC, UNC5H, RET) }\end{array}$ \\
\hline
\end{tabular}

aTypically, a true soluble ligand acts as an antagonist, and promotes apoptosis. Nevertheless, there have been reports in transformed cells where the presence of a

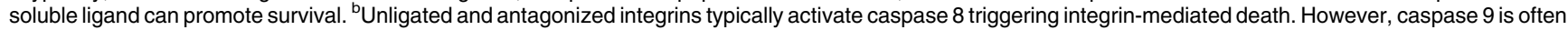
activated downstream of caspase 8 , amplifying the death signal, and can be eventually activated in response to cumulative cell stress due to a lack of 'survival signals' (via anoikis) in cells in which the caspase 8 pathway is inoperative. 
cytosolic domains of the integrins initially lead investigators to search for cytosolic adaptors or kinases that might associate with integrins, and thus mediate the signaling events observed following ligation of substrate ECM. The prototype kinase discovered in the early studies, $\mathrm{FAK},{ }^{37}$ was only the tip of an expanding number of signaling proteins that colocalize with integrins at focal adhesion sites. ${ }^{43,49,73-75}$ In fact, many of these proteins associate with integrins located outside the context of a focal adhesion complex, or in the absence of ligand. $^{73}$

It would not be unreasonable to view these integrinassociated proteins as 'surrogate' cytosolic domains, similar in function to the large kinase and/or adaptor domains that comprise the cytosolic peptides of many signaling receptors, including dependence receptors. ${ }^{4}$ Thus, while integrins themselves do not bear caspase-liberated 'addiction/dependence domains,' caspases do specifically and selectively cleave a number of cytosolic, integrin-associated proteins, including $\mathrm{FAK},{ }^{76,77}$ p130 $\mathrm{CAS},{ }^{78}$ tensin, ${ }^{79}$ paxillin and talin $^{80,81}$ among others. Cleavage of these proteins has been observed during programmed cell death in response to a variety of apoptotic stimuli.

It is worth noting that the products of these cleavage events are themselves often proapoptotic. Much like an addiction/ dependence domain, the expression of recombinant fragments of these integrin-associated proteins can induce apoptosis when expressed independently in cells. Therefore, while integrin cytosolic domains themselves do not appear to be cleaved directly by caspases, the cleavage of these cytosolic, integrin-associated proteins may act analogously to the cleavage of true addiction/dependence domains in canonical dependence receptors.

\section{Signaling cascades and the integrin rheostat}

The expression of dependence receptors in the absence of an appropriate ligand initiates programmed cell death. It is not yet evident whether the induction of programmed cell death by dependence receptors in the absence of ligand may be suppressed by other cell signals, although it seems that direct inhibition of the apoptotic signaling cascades should act to relieve dependence. In the case of integrins, cells can survive with cell surface integrins unligated (or apparently unligated) under a number of conditions.

The most obvious example of nonadherent cell populations are those which are blood-borne, including platelets and cells of the innate and adaptive immune response, as well as stem-cell-like 'precursor cell populations.' These cells are often metabolically quiescent, and tend to regulate their integrins to exist in a low affinity state, as shown by protein conformation and ligand-binding investigations. ${ }^{82-85}$ These conformational changes exist in the extracellular ligand-binding domains and the cytoplasmic domain, ${ }^{86}$ which may influence the capacity to influence apoptosis and cell survival. However, the expression of hematopoietic cellspecific proteins, as well as the quiescent metabolism of these cells, likely also contributes to cell survival in the absence of a substrate ligand.

All cells appear to tolerate some level of unligated integrins without committing to undergo apoptosis. ${ }^{10}$ Important variables would appear to include which specific integrins are ligated by the $\mathrm{ECM}^{34}$ and how rigid the substrate ECM is. ${ }^{87}$ Integrins are mechanoreceptors, able to sense substrate rigidity via periodic contraction of the integrinassociated cytoskeleton. ${ }^{88}$ This results in the recruitment of additional cytoskeletal elements to strengthen the interaction, ${ }^{89}$ which themselves are sensitive to the presence of mechanical force.$^{90}$ Lack of tensional forces may compromise the ability of integrins to mediate productive signaling into the cell, particularly among signaling events that are dependent upon the cytoskeleton. By contrast, signaling via Src kinases does not appear to require significant matrix rigidity. ${ }^{91}$ Therefore, integrins which are potent activators of src kinases, such as $\alpha \mathrm{v} \beta 3$, may permit cellular invasion of less rigid matrices. $^{92}$

These observations go a long way towards explaining why tissue culture plastic provides an excellent foil to counter proapoptotic stimuli; It sustains integrin-cytoskeletal interaction and signaling. Indeed, the cytoskeletal focal complexes observed on cells cultured upon a two-dimensional rigid surface is significantly larger than those observed among cells interacting with a three-dimensional matrix. ${ }^{93}$

The signals arising from these complexes impact the cell's propensity to undergo apoptosis, as described above. Downstream of FAK/Src Family kinases, integrins mediate activation of the small GTPase Ras. ${ }^{39}$ The Ras pathway bifurcates, activating both the MAPK signaling pathway and the PI3K/Akt signaling pathways, each of which potentiates cell survival. ${ }^{94}$ The activation of MAPKs has been linked to integrin-dependent survival in a number of cases. ${ }^{40,51,57,67,95}$ Nevertheless, the activation of PI3K/Akt may be more important at regulating cell viability in the presence of unligated integrins, since constitutively active Akt prevents apoptosis induced via death receptors ${ }^{96-100}$ or active forms of caspase $8 .^{101}$ It is possible that Akt may phosphorylate a peptide loop on caspase 8 proximal to the catalytic site. ${ }^{102}$ Akt activity also compensates for the absence of integrin ligation during cell stresses such as growth factor withdrawal, which results in the activation of caspase 9, implicating Akt as a major mechanism of regulating cell fate (Figure 2). In this respect, inactivation of PTEN, the major phosphatase controlling PI3K/Akt signaling, is commonly observed in tumors, and contributes to the anchorage independence of these cells. ${ }^{103,104}$ Activation of Akt via overexpression of integrin-linked kinase has a similar effect. $^{105}$ While this discussion in not comprehensive, these interactions along the Akt signaling axis provide a mechanism to explain how ligated integrins can mediate signaling events which oppose cell death induced by a variety of proapoptotic stimuli, including unligated integrins. Thus, integrins can be viewed to function as a rheostat. Ligated integrins sense both the composition and relative rigidity of the local ECM, and transmit appropriate signals to the cell. This, in turn, influences the cell's ability to suppress or escalate proapoptotic signaling events. 


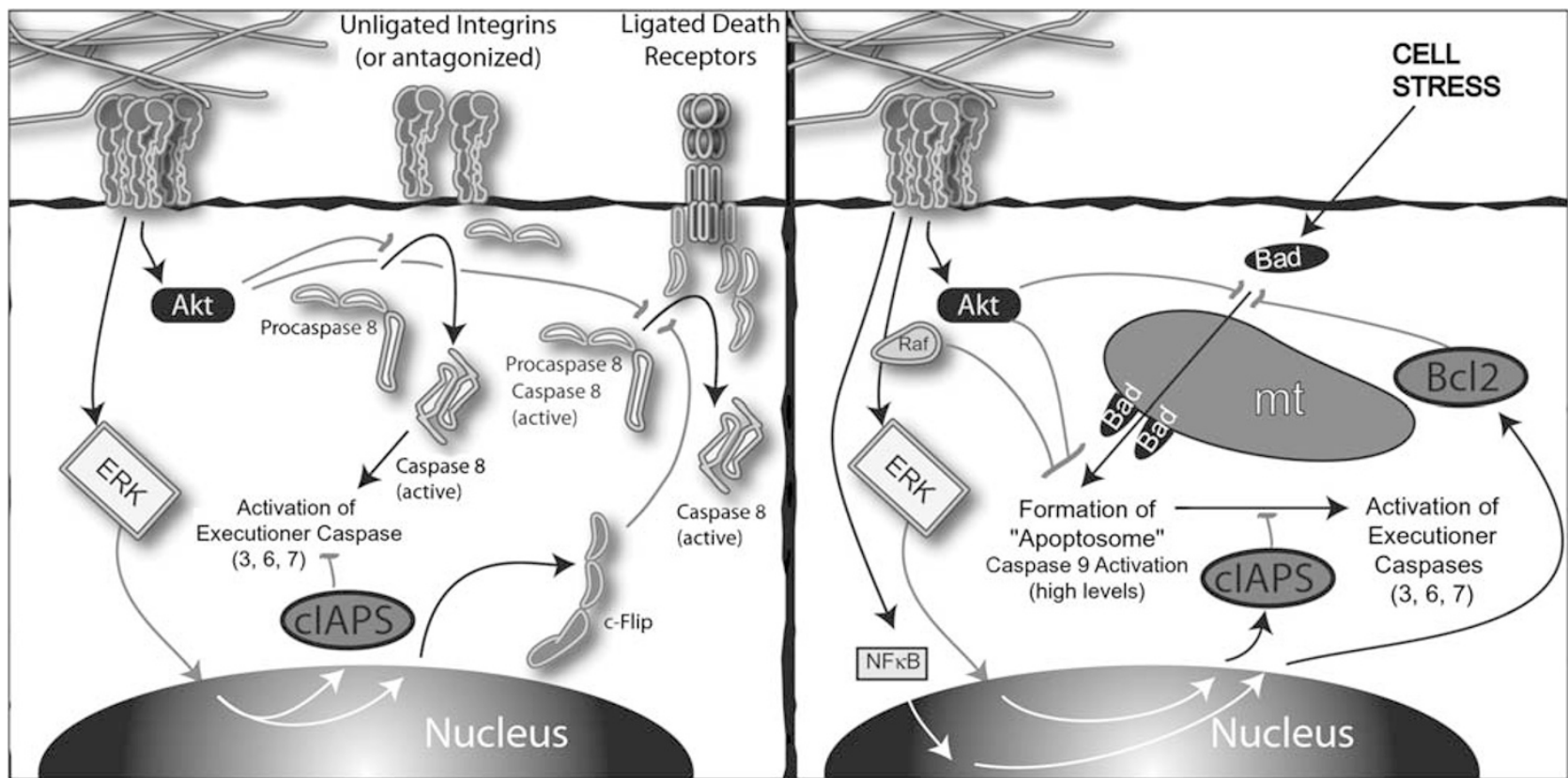

Figure 2 The regulation of cell survival by integrins. The integrins, depicted as $\alpha / \beta$ heterodimers, induce signaling events which impact cell viability as a general event. The right panel indicates integrin interactions that influence apoptosis induced via the intrinsic, or stress pathway, in response to cell stresses such as genotoxic agents or growth factor withdrawal. Integrin-mediated activation of Akt and the ERK pathway via the intermediate Ras-activated protein Raf are shown. Mitochondrial integrity is typically compromised in response to cellular cues activated by cell stresses via the recruitment of BH3 proteins (such as Bad) to the membrane. The release of cytochrome $c$ and other factors permits the formation of the apoptosome, activating caspase 9 , and in turn the executioner caspases. Akt and Raf can act directly on BH3 proteins, and in some cases on caspase 9, preventing the activation of this pathway. Sustained Erk activation (and NF $\kappa$ B activation) induced alterations in cell transcription that result in the production of endogenous inhibitors of this pathway (clAPs, Bcl-2), including protective Bcl2 family proteins (which maintain mitochondrial integrity) and cellular inhibitors of apoptosis (which inhibit caspase 9 and executioner caspases). The left panel depicts the inhibition of apoptosis via the extrinsic pathway triggered by death receptors and unligated integrins. Again, Akt directly inhibits apoptosis induced by caspase 8, regardless of the mechanism by which it is recruited to the membrane (integrins, death receptor or targeted construct). In addition, transcriptional events lead to the expression of c-Flip, which can inhibit precaspase 8 recruitment to ligated death receptor complex, as well as cIAPS, which may ameliorate caspase 8-dependent activation of the mitochondrial pathway (via caspase 9) or the action of the executioner caspases. Note that the ligated and unligated integrins function rheostatically - not only do the unligated integrins fail to transmit survival signals (thereby increasing the cellular propensity to undergo apoptosis) but they also promote the recruitment and activation of caspase 8 at the cell membrane, directly triggering apoptosis

\section{Physiological roles for cellular 'dependence' on the ECM}

The collective data support a function for integrin-mediated cell anchorage in the regulation of tissue homeostasis. The fact that integrins are actin-coupled mechanoreceptors permits them to sense not only the composition but also the relative integrity of the local ECM. These factors may act to ensure that aberrant cells, or cells which become 'misplaced,' fail to thrive. In this context, a cell may be considered misplaced if the ECM surrounding it changes, and the cell does not successfully adapt to the new environment via alterations in integrin expression. This might also occur if the cell migrates into a neighboring tissue with a distinct ECM composition. This biosensor function of integrins acts to regulate routine physiological events, such as epithelial differentiation, ${ }^{18}$ immune cell functions, ${ }^{106,107}$ wound healing events ${ }^{17}$ and angiogenesis. ${ }^{16}$ During these tissue remodeling events, extensive ECM remodeling can occur, and cell survival is influenced not only by the simple presence or absence of ligand but also by the specific forms of a given integrin ligand that are present. In particular, proteolytic cleavage of pre-existing matrix proteins can alter the integrity (and physical rigidity) of the local microenvironment and provide soluble ECM fragments which can antagonize integrin binding to substrate ECM. ${ }^{108}$ When one considers the capacity of integrin-mediated adhesion to modulate both apoptotic and growth factor signaling, the sequential alterations to the ECM that occur during tissue remodeling provide an elegant mechanism to attune the responses of individual cells based on the status of a particular cell's immediate microenvironment.

These same mechanisms that regulate cell survival during physiological tissue remodeling events may also act as first line of defense against tumorigenesis. Cells that spontaneously engage in motile behavior may invade a region of incompatible ECM, or alternatively may modify their local ECM through the production of proteases to produce an incompatible microenvironment. ${ }^{109}$ In either case, the default pathway induced is apoptosis. However, tumors that establish themselves in vivo often find a mechanism to avoid these pitfalls. Many tumors recruit stromal fibroblasts, which both secrete ECM components and apply mechanical tension to the secreted ECM. ${ }^{17,110}$ Some tumors that express an integrin inappropriate to their local ECM simply secrete a required ECM component that permits ligation of the integrin. ${ }^{111,112}$ In others, tumors may activate cytosolic signaling pathways downstream of integrins that regulate apoptosis. As 


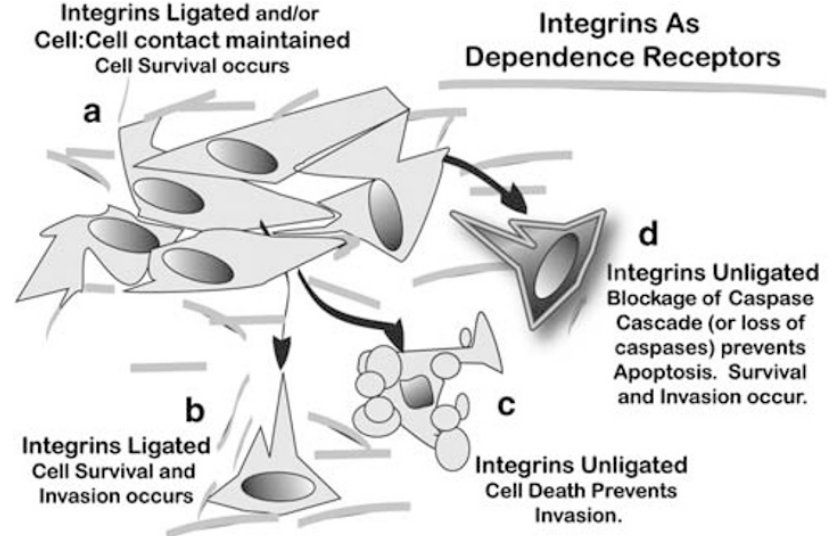

Figure 3 The role of integrins in regulating cell viability during invasion. (a) Noninvasive cells that are engaged in cell:cell and cell:ECM contacts are resistant to apoptotic stimuli. However, during tissue remodeling events or during cell migration, these cells are critically dependent upon the ECM to support cell survival (b). During these events, cellular interaction with an inappropriate ECM, either due to remodeling or entry into neighboring tissues, can result in deficiencies in integrin ligation, directly promoting apoptosis via IMD (c). However, the inhibition of caspase activity by endogenous or exogenous inhibitors or signaling molecules, or the loss of molecules involved in the apoptotic cascade, can prevents this form of apoptosis (d), allowing cellular invasion into tissues despite the presence of an 'inappropriate' ECM

previously mentioned, the Akt pathway can be activated by a number of mechanisms, including loss of the phosphatase PTEN. ${ }^{74}$ Finally, tumors often simply lose or suppress the expression of genes that are required to induce apoptosis. In the case of disseminated neuroendocrine tumors, such as small-cell carcinoma and neuroblastoma, the loss of caspase 8 is associated with malignant disease. ${ }^{113,114}$ Importantly, the frequency with which these events are observed in established tumors suggests that the requirement for integrin ligation by the local ECM imposes an important hurdle that must be overcome during oncogenesis (Figure 3).

\section{Conclusions}

While the concept of 'anchorage dependence' is more than five decades old, the cellular and extracellular protein constituents mediating these events have only been characterized within the last two decades or so. The dependence receptor hypothesis holds that dependence receptors are double-edged swords, mediating positive signaling in the presence of a ligand and negative signaling (leading to cell death) in the absence of an appropriate signal. In this regard, integrins clearly satisfy the requirements of a dependence receptor. However, integrins are intimately tied to one the most basic elements of the cell, the actin cytoskeleton, and thus impact life and death pathways through different mechanisms than many of the canonical dependence receptors. It will be interesting to determine in future studies how integrins interact with the dependence receptors, and to determine whether signaling pathways that alleviate cellular 'dependence' on the ECM via integrins can also impact cell fate governed by dependence on other trophic factors.

\section{References}

1. Hunter T, Lindberg RA, Middlemas DS, Tracy S and van der Geer P (1992) Receptor protein tyrosine kinases and phosphatases. Cold Spring Harb. Symp. Quant. Biol. 57: 25-41

2. Manning G, Plowman GD, Hunter T and Sudarsanam S (2002) Evolution of protein kinase signaling from yeast to man. Trends Biochem. Sci. 27: 514520

3. Patel TB (2004) Single transmembrane spanning heterotrimeric g proteincoupled receptors and their signaling cascades. Pharmacol. Rev. 56: 371385

4. Bredesen DE, Mehlen P and Rabizadeh S (2004) Apoptosis and dependence receptors: a molecular basis for cellular addiction. Physiol. Rev. 84: 411-430

5. Wang $Y$ and Sun $Y$ (2002) Insulin-like growth factor receptor-1 as an anticancer target: blocking transformation and inducing apoptosis. Curr. Cancer Drug Targets 2: 191-207

6. Jones AV and Cross NC (2004) Oncogenic derivatives of platelet-derived growth factor receptors. Cell. Mol. Life Sci. 61: 2912-2923

7. Rabizadeh S, Ye X, Wang JJ and Bredesen DE (1999) Neurotrophin dependence mediated by p75NTR: contrast between rescue by BDNF and NGF. Cell. Death Differ. 6: 1222-1227

8. Mehlen $P$ and Mazelin $L$ (2003) The dependence receptors DCC and UNC5H as a link between neuronal guidance and survival. Biol. Cell 95: 425-436

9. Hynes RO (2002) Integrins: bidirectional, allosteric signaling machines. Cell. 110: $673-687$

10. Giancotti FG (1997) Integrin signaling: specificity and control of cell survival and cell cycle progression. Curr. Opin. Cell. Biol. 9: 691-700

11. Calderwood DA (2004) Integrin activation. J. Cell Sci. 117 (Part 5): 657-666

12. Stupack DG and Cheresh DA (2002) Get a ligand, get a life: integrins, signaling and cell survival. J. Cell Sci. 115 (Part 19): 3729-3738

13. Rupp PA and Little CD (2001) Integrins in vascular development. Circ. Res. 89: $566-572$

14. Drake CJ, Davis LA, Hungerford JE and Little CD (1992) Perturbation of beta 1 integrin-mediated adhesions results in altered somite cell shape and behavior. Dev. Biol. 149: 327-338

15. Brooks PC, Clark RA and Cheresh DA (1994) Requirement of vascular integrin alpha $v$ beta 3 for angiogenesis. Science 264: 569-571

16. Stupack DG and Cheresh DA (2002) ECM remodeling regulates angiogenesis: endothelial integrins look for new ligands. Sci. STKE 2002: E7

17. Gabbiani $G$ (2003) The myofibroblast in wound healing and fibrocontractive diseases. J. Pathol. 200: 500-503

18. Watt FM (2002) Role of integrins in regulating epidermal adhesion, growth and differentiation. EMBO J. 21: 3919-3926

19. Bissell MJ, Weaver VM, Lelievre SA, Wang F, Petersen OW and Schmeichel $\mathrm{KL}$ (1999) Tissue structure, nuclear organization, and gene expression in normal and malignant breast. Cancer Res. 59 (7 Suppl): 1757s-1763s; discussion 1763s-1764s.

20. Barcellos-Hoff MH (1996) Latency and activation in the control of TGF-beta. J. Mammary Gland Biol. Neoplasia 1: 353-363

21. Walch ET, Albino AP and Marchetti D (1999) Correlation of overexpression of the low-affinity p75 neurotrophin receptor with augmented invasion and heparanase production in human malignant melanoma cells. Int. J. Cancer 82: $112-120$

22. Liu ZZ, Wada J, Kumar A, Carone FA, Takahashi M and Kanwar YS (1996) Comparative role of phosphotyrosine kinase domains of c-ros and c-ret protooncogenes in metanephric development with respect to growth factors and matrix morphogens. Dev. Biol. 178: 133-148

23. Singhvi R, Kumar A, Lopez GP, Stephanopoulos GN, Wang DI, Whitesides GM and Ingber DE (1994) Engineering cell shape and function. Science 264 696-698

24. Frisch SM and Ruoslahti E (1997) Integrins and anoikis. Curr. Opin. Cell Biol. 9: $701-706$

25. Frisch SM and Francis $H$ (1994) Disruption of epithelial cell-matrix interactions induces apoptosis. J. Cell Biol. 124: 619-626

26. Meredith Jr JE, Fazeli B and Schwartz MA (1993) The extracellular matrix as a cell survival factor. Mol. Biol. Cell 4: 953-961

27. Schlaepfer DD, Mitra SK and llic D (2004) Control of motile and invasive cell phenotypes by focal adhesion kinase. Biochim. Biophys. Acta 1692 77-102 
28. Jan Y, Matter M, Pai JT, Chen YL, Pilch J, Komatsu M, Ong E, Fukuda M and Ruoslahti E (2004) A mitochondrial protein, Bit1, mediates apoptosis regulated by integrins and Groucho/TLE corepressors. Cell 116: 751-762

29. DeMali KA, Wennerberg $K$ and Burridge $K$ (2003) Integrin signaling to the actin cytoskeleton. Curr. Opin. Cell Biol. 15: 572-582

30. Dalton WS (1999) The tumor microenvironment as a determinant of drug response and resistance. Drug Resist Update 2: 285-288

31. Gendron S, Couture J and Aoudjit F (2003) Integrin alpha2beta1 inhibits Fasmediated apoptosis in T lymphocytes by protein phosphatase $2 \mathrm{~A}$-dependent activation of the MAPK/ERK pathway. J. Biol. Chem. 278: 48633-48643

32. Shain KH, Landowski TH and Dalton WS (2002) Adhesion-mediated intracellular redistribution of c-Fas-associated death domain-like IL-1converting enzyme-like inhibitory protein-long confers resistance to CD95induced apoptosis in hematopoietic cancer cell lines. J. Immunol. 168: 25442553

33. Fornaro M, Plescia J, Chheang S, Tallini G, Zhu YM, King M, Altieri DC and Languino LR (2003) Fibronectin protects prostate cancer cells from tumo necrosis factor-alpha-induced apoptosis via the AKT/survivin pathway. J. Biol. Chem. 278: 50402-50411

34. Zhang Z, Vuori K, Reed JC and Ruoslahti E (1995) The alpha 5 beta 1 integrin supports survival of cells on fibronectin and up-regulates Bcl-2 expression. Proc. Natl. Acad. Sci. USA 92: 6161-6165

35. Stromblad S, Becker JC, Yebra M, Brooks PC and Cheresh DA (1996) Suppression of p53 activity and p21WAF1/CIP1 expression by vascular cell integrin alphaVbeta3 during angiogenesis. J. Clin. Invest. 98: 426-433

36. Tamkun JW, DeSimone DW, Fonda D, Patel RS, Buck C, Horwitz AF and Hynes RO (1986) Structure of integrin, a glycoprotein involved in the transmembrane linkage between fibronectin and actin. Cell 46: 271-282

37. Kornberg L, Earp HS, Parsons JT, Schaller M and Juliano RL (1992) Cell adhesion or integrin clustering increases phosphorylation of a focal adhesionassociated tyrosine kinase. J. Biol. Chem. 267: 23439-23442

38. Giancotti FG and Ruoslahti E (1999) Integrin signaling. Science 285: 10281032

39. Schlaepfer DD, Hanks SK, Hunter T and van der Geer P (1994) Integrinmediated signal transduction linked to Ras pathway by GRB2 binding to focal adhesion kinase. Nature 372: 786-791

40. Aplin AE, Stewart SA, Assoian RK and Juliano RL (2001) Integrin-mediated adhesion regulates ERK nuclear translocation and phosphorylation of Elk-1. J. Cell Biol. 153: 273-282

41. Aoudjit $F$ and Vuori K (2000) Engagement of the alpha2beta1 integrin inhibits Fas ligand expression and activation-induced cell death in T cells in a focal adhesion kinase-dependent manner. Blood 95: 2044-2051

42. Aoudjit $F$ and Vuori $K$ (2001) Matrix attachment regulates Fas-induced apoptosis in endothelial cells: a role for c-flip and implications for anoikis. J. Cell Biol. 152: 633-643

43. Matter ML and Ruoslahti E (2001) A signaling pathway from the alpha5beta1 and alpha(v)beta3 integrins that elevates bcl-2 transcription. J. Biol. Chem. 276: 27757-27763

44. Weintraub AS, Schnapp LM, Lin X and Taubman MB (2000) Osteopontin deficiency in rat vascular smooth muscle cells is associated with an inability to adhere to collagen and increased apoptosis. Lab. Invest. 80: 1603-1615

45. Malyankar UM, Scatena M, Suchland KL, Yun TJ, Clark EA and Giachelli CM (2000) Osteoprotegerin is an alpha vbeta 3-induced, NF-kappa B-dependent survival factor for endothelial cells. J. Biol. Chem. 275: 20959-20962

46. Tapon N and Hall A (1997) Rho, Rac and Cdc42 GTPases regulate the organization of the actin cytoskeleton. Curr. Opin. Cell Biol. 9: 86-92

47. Brahmbhatt AA and Klemke RL (2003) ERK and RhoA differentially regulate pseudopodia growth and retraction during chemotaxis. J. Biol. Chem. 278: 13016-13025

48. Cho SY and Klemke RL (2002) Purification of pseudopodia from polarized cells reveals redistribution and activation of Rac through assembly of a CAS/ Crk scaffold. J. Cell Biol. 156: 725-736

49. Sieg DJ, llic D, Jones KC, Damsky CH, Hunter T and Schlaepfer DD (1998) Pyk2 and Src-family protein-tyrosine kinases compensate for the loss of FAK in fibronectin-stimulated signaling events but Pyk2 does not fully function to enhance FAK-cell migration. EMBO J. 17: 5933-5947

50. Schlaepfer DD and Hunter T (1996) Signal transduction from the extracellula matrix - a role for the focal adhesion protein-tyrosine kinase FAK. Cell. Struct. Funct. 21: $445-450$
51. Cho SY and Klemke RL (2000) Extracellular-regulated kinase activation and CAS/Crk coupling regulate cell migration and suppress apoptosis during invasion of the extracellular matrix. J. Cell Biol. 149: 223-236

52. Smilenov LB, Mikhailov A, Pelham RJ, Marcantonio EE and Gundersen GG (1999) Focal adhesion motility revealed in stationary fibroblasts. Science 286 : 1172-1174

53. Borges E, Jan $Y$ and Ruoslahti E (2000) Platelet-derived growth factor receptor beta and vascular endothelial growth factor receptor 2 bind to the beta 3 integrin through its extracellular domain. J. Biol. Chem. 275: 3986739873

54. Schneller M, Vuori K and Ruoslahti E (1997) Alphavbeta3 integrin associates with activated insulin and PDGFbeta receptors and potentiates the biological activity of PDGF. EMBO J. 16: 5600-5607

55. Sahni A and Francis CW (2004) Stimulation of endothelial cell proliferation by FGF-2 in the presence of fibrinogen requires alphavbeta3. Blood 104: 36353641

56. Eliceiri BP and Cheresh DA (2000) Role of alpha $v$ integrins during angiogenesis. Cancer J. 6 (Suppl. 3): S245-S249

57. Senger DR, Perruzzi CA, Streit M, Koteliansky VE, de Fougerolles AR and Detmar M (2002) The alpha(1)beta(1) and alpha(2)beta(1) integrins provide critical support for vascular endothelial growth factor signaling, endothelial cell migration, and tumor angiogenesis. Am. J. Pathol. 160: 195-204

58. Stupack DG, Puente XS, Boutsaboualoy S, Storgard CM and Cheresh DA (2001) Apoptosis of adherent cells by recruitment of caspase-8 to unligated integrins. J. Cell Biol. 155: 459-470

59. Storgard CM, Stupack DG, Jonczyk A, Goodman SL, Fox RI and Cheresh DA (1999) Decreased angiogenesis and arthritic disease in rabbits treated with an alphavbeta3 antagonist. J. Clin. Invest. 103: 47-54

60. Brassard DL, Maxwell E, Malkowski M, Nagabhushan TL, Kumar CC and Armstrong L (1999) Integrin alpha(v)beta(3)-mediated activation of apoptosis. Exp. Cell Res. 251: 33-45

61. Zhao H, Ross FP and Teitelbaum SL (2005) Unoccupied alpha v beta 3 integrin regulates osteoclast apoptosis by transmitting a positive death signal. Mol. Endocrinol. 19: 771-780

62. Kim S, Bakre M, Yin H and Varner JA (2002) Inhibition of endothelial cell survival and angiogenesis by protein kinase A. J. Clin. Invest. 110: 933-941

63. Marconi A, Atzei P, Panza C, Fila C, Tiberio R, Truzzi F, Wachter T, Leverkus $M$ and Pincelli C (2004) FLICE/caspase-8 activation triggers anoikis induced by beta1-integrin blockade in human keratinocytes. J. Cell Sci. 117 (Part 24): 5815-5823

64. Chicurel ME, Singer RH, Meyer CJ and Ingber DE (1998) Integrin binding and mechanical tension induce movement of mRNA and ribosomes to focal adhesions. Nature 392: 730-733

65. Mazelin L, Bernet A, Bonod-Bidaud C, Pays L, Arnaud S, Gespach C, Bredesen DE, Scoazec JY and Mehlen P (2004) Netrin-1 controls colorectal tumorigenesis by regulating apoptosis. Nature $431: 80-84$

66. Miyazaki T, Shen M, Fujikura D, Tosa N, Kim HR, Kon S, Uede T and Reed JC (2004) Functional role of death-associated protein 3 (DAP3) in anoikis. J. Biol. Chem. 279: 44667-44672

67. Bijian K, Takano T, Papillon J, Khadir A and Cybulsky AV (2004) Extracellular matrix regulates glomerular epithelial cell survival and proliferation. Am. J. Physiol. Renal. Physiol. 286: F255-F266

68. Kim S, Bakre M, Yin $\mathrm{H}$ and Varner JA (2002) Inhibition of endothelial cell survival and angiogenesis by protein kinase A. J. Clin. Invest. 110: 933-941

69. Galvan V, Chen S, Lu D, Logvinova A, Goldsmith P, Koo EH and Bredesen DE (2002) Caspase cleavage of members of the amyloid precursor family of proteins. J. Neurochem. 82: 283-294

70. Yamazaki T, Koo EH and Selkoe DJ (1997) Cell surface amyloid beta-protein precursor colocalizes with beta 1 integrins at substrate contact sites in neural cells. J. Neurosci. 17: 1004-1010

71. Huttenlocher A, Palecek SP, Lu Q, Zhang W, Mellgren RL, Lauffenburger DA, Ginsberg MH and Horwitz AF (1997) Regulation of cell migration by the calcium-dependent protease calpain. J. Biol. Chem. 272: 32719-32722

72. Du X, Saido TC, Tsubuki S, Indig FE, Williams MJ and Ginsberg MH (1995) Calpain cleavage of the cytoplasmic domain of the integrin beta 3 subunit. J. Biol. Chem. 270: 26146-26151

73. Lewis JM, Cheresh DA and Schwartz MA (1996) Protein kinase C regulates alpha $v$ beta 5 -dependent cytoskeletal associations and focal adhesion kinase phosphorylation. J. Cell Biol. 134: 1323-1332 
74. Tamura M, Gu J, Danen EH, Takino T, Miyamoto S and Yamada KM (1999) PTEN interactions with focal adhesion kinase and suppression of the extracellular matrix-dependent phosphatidylinositol 3-kinase/Akt cell survival pathway. J. Biol. Chem. 274: 20693-20703

75. Eliceiri BP, Puente XS, Hood JD, Stupack DG, Schlaepfer DD, Huang XZ, Sheppard D and Cheresh DA (2002) Src-mediated coupling of focal adhesion kinase to integrin alpha(v)beta5 in vascular endothelial growth factor signaling. J. Cell Biol. 157: 149-160

76. Gervais FG, Thornberry NA, Ruffolo SC, Nicholson DW and Roy S (1998) Caspases cleave focal adhesion kinase during apoptosis to generate a FRNK-like polypeptide. J. Biol. Chem. 273: 17102-17108

77. Wen LP, Fahrni JA, Troie S, Guan JL, Orth K and Rosen GD (1997) Cleavage of focal adhesion kinase by caspases during apoptosis. J. Biol. Chem. 272 26056-26061

78. Wei L, Yang Y, Zhang X and Yu Q (2004) Cleavage of p130Cas in anoikis. J. Cell Biochem. 91: 325-335

79. Kook S, Kim do H, Shim SR, Kim W, Chun JS and Song WK (2003) Caspasedependent cleavage of tensin induces disruption of actin cytoskeleton during apoptosis. Biochem. Biophys. Res. Commun. 303: 37-45

80. Chay KO, Park SS and Mushinski JF (2002) Linkage of caspase-mediated degradation of paxillin to apoptosis in $\mathrm{Ba} / \mathrm{F} 3$ murine pro- $\mathrm{B}$ lymphocytes. J. Biol. Chem. 277: 14521-14529

81. Lesay A, Hickman JA and Gibson RM (2001) Disruption of focal adhesions mediates detachment during neuronal apoptosis. NeuroReport 12: 2111 2115

82. Miyamoto YJ, Andruss BF, Mitchell JS, Billard MJ and Mclntyre BW (2003) Diverse roles of integrins in human T Iymphocyte biology. Immunol. Res. 27 : $71-84$

83. Calvete JJ (2004) Structures of integrin domains and concerted conformational changes in the bidirectional signaling mechanism of alphallbbeta3. Exp. Biol. Med. (Maywood) 229: 732-744

84. Hogg N, Henderson R, Leitinger B, McDowall A, Porter J and Stanley P (2002) Mechanisms contributing to the activity of integrins on leukocytes. Immunol. Rev. 186: 164-171

85. Springer TA and Wang JH (2004) The three-dimensional structure of integrins and their ligands, and conformational regulation of cell adhesion. Adv. Protein Chem. 68: 29-63

86. Vinogradova O, Velyvis A, Velyviene A, Hu B, Haas T, Plow E and Qin J (2002) A structural mechanism of integrin alpha(Ilb)beta(3) 'inside-out' activation as regulated by its cytoplasmic face. Cell 110 : 587-597

87. Koo LY, Irvine DJ, Mayes AM, Lauffenburger DA and Griffith LG (2002) Coregulation of cell adhesion by nanoscale RGD organization and mechanical stimulus. J. Cell Sci. 115 (Part 7): 1423-1433

88. Giannone G, Dubin-Thaler BJ, Dobereiner HG, Kieffer N, Bresnick AR and Sheetz MP (2004) Periodic lamellipodial contractions correlate with rearward actin waves. Cell 116: 431-443

89. Choquet D, Felsenfeld DP and Sheetz MP (1997) Extracellular matrix rigidity causes strengthening of integrin-cytoskeleton linkages. Cell 88: 39-48

90. Jiang G, Giannone G, Critchley DR, Fukumoto E and Sheetz MP (2003) Twopiconewton slip bond between fibronectin and the cytoskeleton depends on talin. Nature 424: 334-337

91. Galbraith CG, Yamada KM and Sheetz MP (2002) The relationship between force and focal complex development. J. Cell Biol. 159: 695-705

92. Vailhe $B$, Ronot $X$, Tracqui $P$, Usson $Y$ and Tranqui $L$ (1997) In vitro angiogenesis is modulated by the mechanical properties of fibrin gels and is related to alpha(v)beta3 integrin localization. In Vitro Cell. Dev. Biol. Anim. 33: 763-773

93. Yamada KM, Pankov R and Cukierman E (2003) Dimensions and dynamics in integrin function. Braz. J. Med. Biol. Res. 36: 959-966

94. Xue L, Murray JH and Tolkovsky AM (2000) The Ras/phosphatidylinositol 3kinase and Ras/ERK pathways function as independent survival modules each of which inhibits a distinct apoptotic signaling pathway in sympathetic neurons. J. Biol. Chem. 275: 8817-8824
95. Howe AK, Aplin AE and Juliano RL (2002) Anchorage-dependent ERK signaling - mechanisms and consequences. Curr. Opin. Genet. Dev. 12: 30-35

96. Chen X, Thakkar H, Tyan F, Gim S, Robinson H, Lee C, Pandey SK, Nwokorie C, Onwudiwe N and Srivastava RK (2001) Constitutively active Akt is an important regulator of TRAIL sensitivity in prostate cancer. Oncogene 20: 6073-6083

97. Miyashita T, Kawakami A, Tamai M, Izumi Y, Mingguo H, Tanaka F, Abiru S, Nakashima K, Iwanaga N, Aratake K, Kamachi M, Arima K, Ida H, Migita K Origuchi T, Tagashira S, Nishikaku F and Eguchi K (2003) Akt is an endogenous inhibitor toward tumor necrosis factor-related apoptosis inducing ligand-mediated apoptosis in rheumatoid synovial cells. Biochem. Biophys. Res. Commun. 312: 397-404

98. Nesterov A, Lu X, Johnson M, Miller GJ, Ivashchenko Y and Kraft AS (2001) Elevated AKT activity protects the prostate cancer cell line LNCaP from TRAIL-induced apoptosis. J. Biol. Chem. 276: 10767-10774

99. Park SY and Seol DW (2002) Regulation of Akt by EGF-R inhibitors, a possible mechanism of EGF-R inhibitor-enhanced TRAIL-induced apoptosis. Biochem. Biophys. Res. Commun. 295: 515-518

100. Ho R, Eggert A, Hishiki T, Minturn JE, Ikegaki N, Foster P, Camoratto AM, Evans AE and Brodeur GM (2002) Resistance to chemotherapy mediated by TrkB in neuroblastomas. Cancer Res. 62: 6462-6466

101. Li L, Okura M and Imamoto A (2002) Focal adhesions require catalytic activity of Src family kinases to mediate integrin-matrix adhesion. Mol. Cell. Biol. 22 1203-1217

102. Shim D, Kang HY, Jeon BW, Kang SS, Chang SI and Kim HY (2004) Protein kinase B inhibits apoptosis induced by actinomycin D in ECV304 cells through phosphorylation of caspase 8. Arch. Biochem. Biophys. 425: 214-220

103. Lu Y, Lin YZ, LaPushin R, Cuevas B, Fang X, Yu SX, Davies MA, Khan H, Furui T, Mao M, Zinner R, Hung MC, Steck P, Siminovitch $K$ and Mills GB (1999) The PTEN/MMAC1/TEP tumor suppressor gene decreases cell growth and induces apoptosis and anoikis in breast cancer cells. Oncogene 18: 7034-7045

104. Parsons R (2004) Human cancer, PTEN and the PI-3 kinase pathway. Semin. Cell Dev. Biol. 15: 171-176

105. Attwell S, Roskelley C and Dedhar S (2000) The integrin-linked kinase (ILK) suppresses anoikis. Oncogene 19: 3811-3815

106. Leussink VI, Zettl UK, Jander S, Pepinsky RB, Lobb RR, Stoll G, Toyka KV and Gold $R$ (2002) Blockade of signaling via the very late antigen (VLA-4) and its counterligand vascular cell adhesion molecule-1 (VCAM-1) causes increased $T$ cell apoptosis in experimental autoimmune neuritis. Acta Neuropathol. (Berl) 103: 131-136

107. Yan SR, Sapru K and Issekutz AC (2004) The CD11/CD18 (beta2) integrins modulate neutrophil caspase activation and survival following TNF-alpha or endotoxin induced transendothelial migration. Immunol. Cell Biol. 82: 435-446

108. Stupack DG and Cheresh DA (2003) Apoptotic cues from the extracellular matrix: regulators of angiogenesis. Oncogene 22: 9022-9029

109. Fata JE, Werb $Z$ and Bissell MJ (2004) Regulation of mammary gland branching morphogenesis by the extracellular matrix and its remodeling enzymes. Breast Cancer Res. 6: 1-11

110. Bogenrieder T and Herlyn M (2003) Axis of evil: molecular mechanisms of cancer metastasis. Oncogene 22: 6524-6536

111. Gladson CL and Cheresh DA (1991) Glioblastoma expression of vitronectin and the alpha $v$ beta 3 integrin. Adhesion mechanism for transformed glial cells. J. Clin. Invest. 88: 1924-1932

112. Pupa SM, Menard S, Forti S and Tagliabue E (2002) New insights into the role of extracellular matrix during tumor onset and progression. J. Cell Physiol. 192: 259-267

113. Teitz T, Wei T, Valentine MB, Vanin EF, Grenet J, Valentine VA, Behm FG, Look AT, Lahti JM and Kidd VJ (2000) Caspase 8 is deleted or silenced preferentially in childhood neuroblastomas with amplification of MYCN. Nat. Med. 6: 529-535

114. Shivapurkar N, Toyooka S, Eby MT, Huang CX, Sathyanarayana UG, Cunningham HT, Reddy JL, Brambilla E, Takahashi T, Minna JD, Chaudhary PM and Gazdar AF (2002) Differential inactivation of caspase-8 in lung cancers. Cancer Biol. Ther. 1: 65-69 